\title{
Ethics Applied in ICU For Rehabilitation Care in Users with Oncological Disease and Compromised Renal Function
}

\author{
Jorge Enrique Moreno-Collazos*1, Eva Segura Orti², Diana Carolina Zona Rubio ${ }^{3}$ and Julián Alberto Moreno ${ }^{4}$ \\ ${ }^{1}$ Physiotherapist, Specialist in Cardiopulmonary Rehabilitation. Master of Science in Physical Activity and Sports. PhD in public health, Manuela \\ Beltrán University, Avenida Circunvalar № 60-00 Bogotá, Cundinamarca, Colombia \\ ${ }^{2}$ Physiotherapist, PhD in Physiotherapy, Teacher and researcher, Physiotherapy Department, Cardenal Herrera University, Valencia, España \\ ${ }^{3}$ Respiratory Therapist Specialist in respiratory therapy in critical care, Candidate to Master of Science-Pharmacology, Teachers researcher of \\ the Cardiorespiratory Therapy Unit, Manuela Beltrán University, Colombia \\ ${ }^{4}$ Collazos, Physical Culturist, Occupational Health Specialist, Minuto de Dios University, Colombia
}

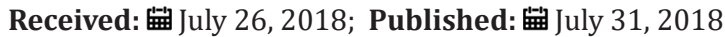

*Corresponding author: Jorge Enrique Moreno-Collazos, Physiotherapist, Specialist in Cardiopulmonary Rehabilitation. Master of Science in Physical Activity and Sports, PhD in public health, Manuela Beltrán University, Avenida Circunvalar № 60-00 Bogotá, Cundinamarca, Colombia

\begin{abstract}
Renal rehabilitation based on early body movement in intensive care units that has been expanding its fields of action from the areas of health promotion, disease prevention, maintenance and rehabilitation of people from the center of study human body movement applied in comprehensive care in intensive care units, which leads to reflection on a reflective theoretical discernment process of conceptual elements that lead to understand the ethical vision of the concept of body and movement in a hospitalization context from the renal environment where key aspects such as pain, care, dysfunctions, limitations and disabilities resulting from the immobilization process are articulated in the bioethical principles from the praxis of human movement.
\end{abstract}

Keywords: Ethics; Renal Insufficiency; Intensive Care; Rehabilitation.

\section{Introduction}

The body movement induced in renal rehabilitation within its conception indicates a historical and contemporary vision immersed in some gender norms that are strongly intertwined in corporal representations during their professional training cycle [1]. In recent years, renal rehabilitators have shown increasing interest in defining their professional identity and in responding to their fundamental role on the concept of the body from practice $[2,3]$. With some notable exceptions, the body is conceived from a philosophical / theoretical perspective from a construction that has been almost totally outside the profession offering a sociohistorical critique of the role that the body has played in the practical definition from the clinic. [4].

Thus, corporeity expresses itself as the materiality of human existence with its potentialities and wear and tear; an organic, anatomical and morphological materiality on which the health-disease processes relapse. Corporality goes beyond the mere biological, physiological and technical explanation of body movement; this concept has been extended to incorporate its sensitivity, sensory and sensitivity; both speak of personal experiences and existences. With this idea the understanding of meanings, imaginaries, representations and expressions of the body and movement is introduced. Palliative care, as a set of medico-social measures aimed at improving the quality of life of terminally ill patients and supporting their family, has undergone a very significant development in the last 10 years. Its strengthening has exerted a remarkable positive influence on health institutions and social services not only because it has generalized that when it cannot be cured, it is possible to alleviate frequently and always comfort, but because it has given origin and strength to a solidarity movement in favor of a better terminal condition [5].

Physiotherapy in terminal care does not seem to have a welldefined endpoint. It can be applied throughout the continuum of care from the moment of diagnosis until the end of life and can 
involve both psychological and physical aspects [6]. Although the objectives of the intervention in critical care have been constituted in a clear decision-making based on scientific evidence, some results inherent to the therapeutic modalities regarding the condition of their musculoskeletal, neuromuscular, are still unknown. pulmonary and integumentary cardiovascular within its intrahospital management $[7,8]$.

\section{Methodology}

The exercise of the rehabilitation of the critical care units evidences an important exercise in the professional autonomy that is based on the ethical aspect in the decision making based on the significance of the social need articulated with the current inherent needs of the practice based on the evidence that allows to review current models of physiotherapist care in intensive care units $[9,10]$.

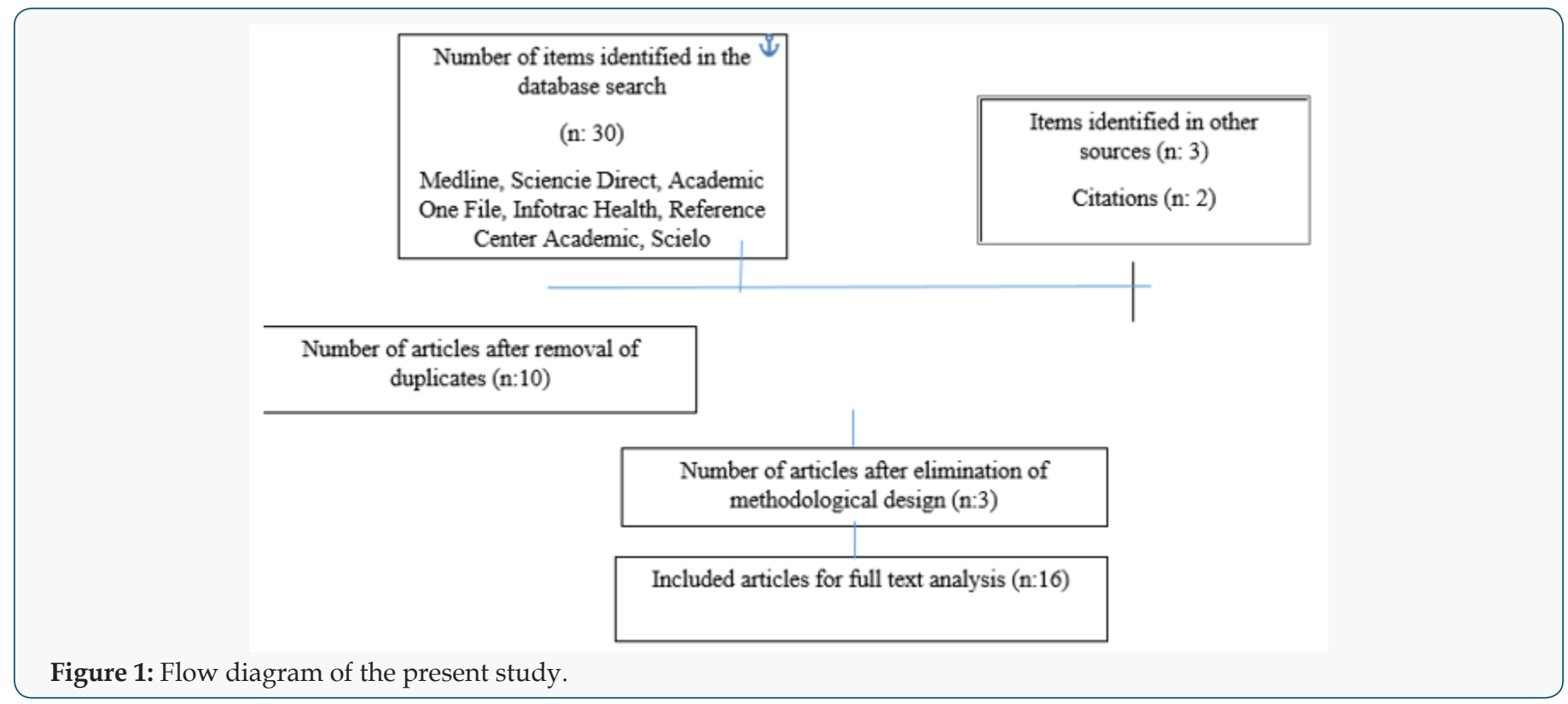

In order to define the limits of publications on unique ethical issues for the practice of rehabilitation in intensive care units from the component of human body movement and also to define the major issues of ethical interest; an extensive literature search was carried out using search engines such as: Medline, Science Direct, Academic One File, Infotrac Health, Reference Center Academic, Scielo, in English, Spanish, and Portuguese in a preponderant manner with search terms: physiotherapy, renal failure, neoplasia, ethics, critical care, rehabilitation, movement, which was limited to the last 10 years. We managed to recover 30 articles, but only 16 articles were relevant for the reflection of ethical issues from the physiotherapy that are taken into account for the area of care in the user with chronic kidney disease in relation to the concepts of user care in terminal state, end of life, ethics, palliative care, health services articulated with the principles of autonomy, beneficence, nonmaleficence and justice to determine important actions and challenges of renal rehabilitation in intensive care units (Figure 1).

\section{Results}

When reviewing the literature, it is evident that the prospect of being in the developed world, the end-of-life treatment usually focuses on the patient's comfort and assumes less aggressive therapies [11,12]. This is evident in the concept of professional autonomy that is defined as a social contract based on the trust of the public to which the discipline is directed with the objective of satisfying a social significance [13]. Now we identify the four basic principles of bioethics that must condition the behavior of the physiotherapist in critical conditions and that serve to give a methodological value in the decision making, as they are established in the work of Beauchamp and Childress [14] where the following ethical principles are established in praxis: The non-maleficence, which requires not to harm others (primun non necere) and to perform our professional work correctly.

It is translated into protocols that reflect the requirements of good clinical practice. The treatment must provide more benefit than risk or danger to the patient. This principle is violated when a treatment is applied to a patient that is not indicated, which causes an avoidable complication, damage or any type of injury. It is not uncommon for intensive care units to arrive at a time when interventions do not actually act to prolong an acceptable life, but rather prolong an inevitable death process. Thus, for example, administering antibiotics for an infection in patients in irreversible coma or perform cardiopulmonary resuscitation maneuvers in terminal patients is to avoid a painless death to prolong an agonizing situation that, often, is accompanied by pain and lack of dignity.

Justice, which obliges us to provide all people with the same opportunities in the social order, without discrimination, segregation or marginalization and the correct administration of health resources, mostly public. The principle of justice requires that the distribution of resources be equitable: for this reason, administering unlimited or uncontrolled resources to 
unrecoverable patients can exclude, and undoubtedly do, others in more need. Although the obligation of justice is the responsibility of the health authorities and managers, the scarcity of resources is not enough to justify the decisions of limiting the therapeutic effort, but it is our responsibility or subsidiary.

Autonomy, which is the ability of people to perform acts with knowledge of cause, sufficient information and in the absence of internal or external coercion, that is, the "informed consent". A competent user has the right to accept or refuse medical treatment or to delegate his decision to someone acting on his behalf when he cannot do so $[15,16]$.

The beneficence, which forces us to do well, according to the criteria of the possible beneficiary. The health professional must help the patient to cope and reduce the impact of the disease. Because of this principle, the doctor has to take responsibility for fulfilling the objectives of the discipline in the rehabilitation scheme $[17,18]$, which we can summarize in treating the patient as best as possible, restoring his health, preserving his life and alleviating his suffering. Sometimes these concepts may conflict. In the ICU, not everything technically possible is beneficial for the patient, and sometimes submitting to certain procedures can be harmful, thereby violating the previous principles.

These ethical principles are normative criteria of behavior, which introduce the guarantee of an argumentative rationality in the decision making in the physiotherapist, but by themselves they are insufficient $[18,19]$. Conflicts that arise at the end of life can be resolved with prudence, which consider it as the central concept in palliative care and even in all health care of the interdisciplinary team $[20,21]$.

\section{Discussion}

Professional ethics as a cornerstone in the care of people with cancer in intensive care units generates an important debate to know conceptual elements that should be permeated in the training curricula and their transition in clinical practices in the care of the user with illness Oncology to be able to consolidate in the integration of competences from the understanding, analysis, of the ethical concepts in the physiotherapeutic diagnosis from the limitations, dysfunctions and disability to which they are confronted in the stays of the intensive care units from the interprofessional dialogue [22-24]. In the study of human body movement rehabilitation, it is essential to approach the user from the sensitive moral perspective articulated with the ethical situations faced by health system organizations and levels of society where they are developing their professional work [25-27].

It is recognized as an identified problem the determination of the objectives and the limits of the treatment that is established in the user, in those situations where the professional supports the Oncological and renal Rehabilitation team, being an important factor the physical emotional relationship of the therapist attention - patient where the quality of care with humanization are key to the adherence in the intervention from the human body movement $[28,29]$. Evidence-based practice must be analyzed from a criticalreflective point of view given that the various research results in applied works are able to observe an ambiguity in the ethical principles assumed from the proposed scientific methodology that are sometimes conflict and implications in the clinical practice [30].

\section{Thanks}

Special recognition is given to the team of professors and researchers of the cardiorespiratory therapy postgraduate program of the Manuela Beltrán University and institutions that collaborated in discernment on key issues of ethical aspects that influence the attention of users with limitation, dysfunction or situation. of disability with the perspective of contributing to the foundation of rehabilitation programs aimed at groups and communities.

\section{References}

1. Tone Dahl Michelsen (2014) When bodies matter: significance of the body in gender constructions in physiotherapy education. Gender and Education 26(6): 672-687.

2. Cash TF (2004) Body image: Past, present, and future. Body image $1(1): 1-5$.

3. Nicholls DA, Gibson BE (2010) The body and physiotherapy. Physiotherapy Theory \& Practice 26(8): 497-509.

4. Stiller K (2000) Physiotherapy in intensive care: towards an evidencebased practice. Chest 118(6): 1801-1813.

5. Morales-Caro MS, Torres-Baquero M (2013) Acercamiento y comprensión del cuerpo-sujeto en la kinesiterapia: una experiencia académica. Revista de la Facultad de Medicina 61(4): 477-482.

6. Astudillo W, Mendinueta C, Orbegozo A (2002) Presente y futuro de los Cuidados Paliativos. Astudillo W, Morales A, Clavé E, Cabarcos A, Urdaneta E.Avances recientes en Cuidados Paliativos. San Sebastián: Ed.Sociedad Vasca de Cuidados Paliativos p. 15-46.

7. Poulis I (2007) Bioethics and physiotherapy. J Med Ethics 33(8): 435436.

8. Poulis I (2007) The end of physiotherapy. Australian Journal of Physiotherapy 53(2): 71-72.

9. Vitacca M, Barbano L, Vanoglio F, Luisa A, Bernocchi P, et al. (2016) Does 6-Month Home Caregiver-Supervised Physiotherapy Improve PostCritical Care Outcomes? A Randomized Controlled Trial. Am J Phys Med Rehabil 95(8): 571-579.

10. Maehr B, Keilani M, Wiltschke C, Hassler M, Licht T, et al. (2016) Cancer rehabilitation in Austria-aspects of Physical Medicine and Rehabilitation. Wiener Medizinische Wochenschrift 166(1-2): 39-43.

11. Aniebue UU, Onyeka TC (2014) Ethical, socioeconomic, and cultural considerations in gynecologic cancer care in developing countries. International Journal of Palliative Care pp. 1-6.

12. Chigbo NN, Ezeome ER, Onyeka TC, Amah CC (2015) Ethics of physiotherapy practice in terminally ill patients in a developing country, Nigeria. Niger J Clin Pract 18 Suppl: S40-S45.

13. Praestegaard J, Gard G (2013) Ethical issues in physiotherapyReflected from the perspective of physiotherapists in private practice. Physiotherapy theory and practice 29(2): 96-112.

14. Beauchamp TL, Childress JF (2001) Principles of biomedical ethics. Oxford University Press, USA pp. 1-480.

15. Nadler M, Bainbridge D, Tomasone J, Cheifetz O, Juergens RA, et al. (2017) Oncology care provider perspectives on exercise promotion in 
people with cancer: an examination of knowledge, practices, barriers, and facilitators. Supportive Care in Cancer 25(7): 2297-2304.

16. Stein GL, Kerwin J (2017) Chapter: (p.503) Social Work and Bioethics: Enhanced Resolution of Ethical Dilemmas and the Challenges along the Way.

17. Bembibre Taboada RM (2003) Aspectos éticos-bioéticos en la atención del paciente crítico. Rev Cubana Med 42(1): 5-11.

18. Drolet M, Hudon A (2015) Theoretical frameworks used to discuss ethical issues in private physiotherapy practice and proposal of a new ethical tool. Medicine, health care and philosophy 18(1): 51-62.

19. Santuzzi CH, Scardua MJ, Reetz JB, Firme KS, Lira NO, et al. (2013) Aspectos éticos e humanizados da fisioterapia na UTI: uma revisão sistemática. Fisioterapia em Movimento 26(2).

20. Edwards I, Braunack Mayer A, Jones M (2005) Ethical reasoning as a clinical-reasoning strategy in physiotherapy. Physiotherapy 91(4): 229 236.

21. Strawbridge JD, Barrett AM, Barlow JW (2014) Interprofessional ethics and professionalism debates: findings from a study involving physiotherapy and pharmacy students. Journal of interprofessional care 28(1): 64-65.

22. Greenfield BH, Jensen GM (2010) Understanding the lived experiences of patients: Application of a phenomenological approach to ethics. Phys Ther 90(8): 1185-1197.
23. Cross S, Sim J (2000) Confidentiality within physiotherapy: perceptions and attitudes of clinical practitioners. J Med Ethics 26(6): 447-453.

24. Nalette E (2010) Constrained physical therapist practice: an ethical case analysis of recommending discharge placement from the acute care setting. Phys Ther 90(6): 939-952.

25. Sisola SW (2000) Moral reasoning as a predictor of clinical practice: The development of physical therapy students across the professional curriculum. Journal of Physical Therapy Education 14(3): 26

26. Goethals S, Gastmans C, de Casterlé BD (2010) Nurses' ethical reasoning and behaviour: a literature review. Int J Nurs Stud 47(5): 635-650.

27. Swisher LL, Hiller P (2010) The revised APTA code of ethics for the physical therapist and standards of ethical conduct for the physical therapist assistant: theory, purpose, process, and significance. Phys Ther 90(5): 803-824

28. Kulju K, Suhonen R, Leino-Kilpi H (2013) Ethical problems and moral sensitivity in physiotherapy: A descriptive study. Nurs Ethics 20(5): 568577.

29. Guccione AA (1980) Ethical issues in physical therapy practice. Phys Thern 60(10): 1264-1272.

30. Kumar S, Grimmer Somers K, Hughes B (2010) The ethics of evidence implementation in health care. Physiotherapy Research International 15(2): 96-102.

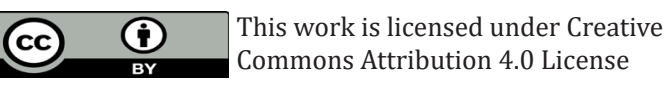

To Submit Your Article Click Here:

Submit Artic

DOI: $10.32474 / J U N S .2018 .01 .000110$

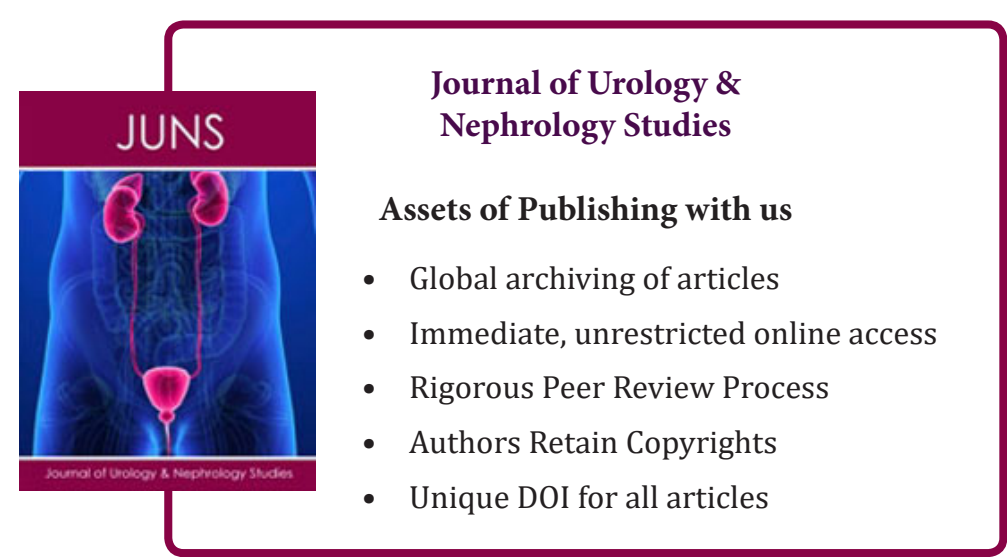

